\author{
Парфенюкова Е.А., асс., магистрант \\ Белгородский государствениый технологический университет и.м. В.Г. Шухова \\ Ширина Н.В., канд. техн. наук, доц. \\ Белгородский государствениьй аграрный университет и.м. В.Я. Горина
}

\title{
ПРАВОВЫЕ ОСНОВЫ И РЕГУЛИРОВАНИЕ ОЦЕНОЧНОЙ ДЕЯТЕЛЬНОСТИ
}

\begin{abstract}
schnv02@mail.ru
Приводятся основные положения регулирования оценочной деятельности в РФ на современном этапе, а именно, рассматривается действуюиая система регулирования оченочной деятельности, состолиал из федерального закона 시 35-Ф3 и системы стандартов; проведена четкал грань между тремя уровнями системь регулирования оценочной деятельности и строго разграничень полномочия в этой сфере.
\end{abstract}

Ключевые слова: оченочная деятельность, саморегулируемые оргапизации, федеральные стандартыл оченки, регулирование оченки.

Под оценочной деятельностью в законодательстве Российской Федерации понимается профессиональная деятельность субъъектов оценочной деятельности - специалистовоценщиков, направ.ленная на установление рыночной или иной стоимости (инвестиционной, ликвидной и др.) объектов гражданских прав (недвижимого и движимого имущества, в том числе имушественных прав, работ и услуг, информации, результатов интеллектуальной деятельности и прав на них, нематериальных благ) [1].

Результаты оценки используются различными участниками рынка. Например, при рассмотрении имущественных споров, когда каждая из сторон преследует свой экономический интерес, нередко обрашаются к оценщикам. В таких условиях нередко возникает проблема противостояния оценщика давлению заинтересованных сторон или различных обстоятельств. Очевидно, что встает вопрос об обеспечении единообразных и унифицированных подходов к оценке, о разработке соответствующих механизмов, основанных на принципах сбалансированного сочетания государственного и негосударственного контроля, осуществлясмого в цслях обеспечения защиты интересов потребителя оценочных услуг и третьих лиц, т.е. о регулировании оценочной деятельности.

Действующая система регулирования оценочной деятельности в России сложилась постепенно, по мере развития как рыночных отношений, связанных с оценкой, так и нормативной базы.

Достаточно долгий период, до 1998 года, оценочная деятельность в России осуществлялась без полноценного нормативно-правового регулирования. Первая редакция Закона об оценке была принята только 29.07.1998 г. До этого момента оценка выполнялась в зависимо- сти от внутренних представлений конкретного «оценщика» и заказчика его работ (более того, до 1996 года отсутствовала даже сама профессия «оценщик»).

Например, многие отчеты об оценке начала 90-х годов XX века представляли собой брошюры объемом в 10-15 страниц, из которых непосредственно к расчету стоимости относились примерно 2-3 страницы (прочие включали: титульный лист, оглавление, сопроводительное письмо-обращение, описание регалий и опыта работы оценщика, список использованных источников, копии разного рода благодарственных писем).

Сегодня оценочная деятельность осуществлястся в соответствии с международными договорами Российской Федерации, федеральными законами и иными нормативными правовыми актами Российской Федерации, регулирующими отношсния, возникающис при осушествлснии оценочной деятельности. Законодательными и иными нормативными правовыми актами субъектов РФ оценочная деятельность регулироваться не может [2]. Правовыс основы регулирования оцсночной деятельности в отношении объектов оценки, принадлежащих Российской Федерации, субъъектам Российской Федерации или муниципальным образованиям, физическим лицам и юридическим лицам, для целей совершения сделок с объектами оценки, а также для иных целей определяет Федеральный закон, принятый 29 июля 1998 г. № 135-ФЗ «Об оценочной деятельности в Российской Федерации», который многократно подвергался редакционным изменениям и действует по настоящее время [1].

Он закрепляет общие нормы, регулирующие оценочную деятельность, с которыми должны быть согласованы касающиеся оценочной деятельности нормы отраслевого законода- 
те.ьства (гражданского законодательства, законодательства о приватизации, об исполнительном производстве, о бухгалтерском учете, о налогах и сборах и т.д.).

Закон носит характер специального. Это означает, что если существуют противоречия между нормами общего и специального закона, то руководствоваться следует нормами последнего. Нормы Закона детализируются в постановлениях Правительства России и федеральных органов исполнительной власти, уполномоченных Правительством РФ на осуществление надзора и нормативно-правового регулирования оценочной деятельности и деятельности СРО.

Отметим, что некоторые нормы Закона закреплены на основании положений Международных стандартов оценки, разработанных Международным комитетом по стандартам оценки имущества (МКСОИ, The International Assets Valuation Standards Committee, TIAVSC). Кроме того, Европейской группой ассоциаций оценщиков (ЕГАО) приняты Европейские стандарты оценки (ЕСО) (рис. 1) [3, 4].

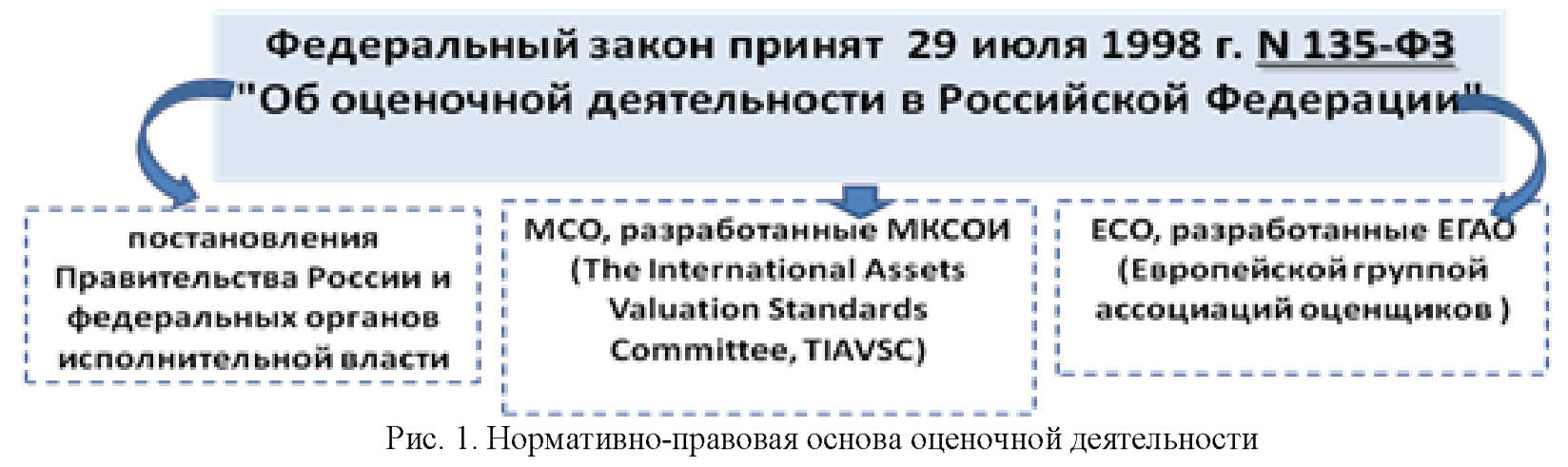

В первой главе Закона дается определение понятия «оценочная деятельность», определяется субъектный состав отношений, объекты оценки, закреплено право Российской Федерации, ее субъектов и муниципальных образований, т.е. публичных образований, а также физических лиц и юридических лиц, т.е. частных и корпоративных лиц, на проведение оценки любых принадлежащих им объектов оценки, установлена презумпция определения рыночной стоимости при оценке объектов, предусмотрены случаи обязательного проведения оценки.

Вторая глава Закона посвящена основаниям для проведения оценочной деятельности. Глава определяет обязательные требования к договору на проведение оценки, требования к содсржанию отчета о провсдснии оценки, прсдусматривает возможность судеб́ного оспаривания достоверности величины рыночной или иной стоимости объекта оценки, установленной в отчете оценщика, устанавливает права и обязанности оценшика и лица, заключившего с ним договор, прсдусматриваст нсзависимость оцснщика.

Третья глава посвящена регулированию оценочной деятельности. В ней установлен порядок рсгулирования оценочной деятельности, функции уполномоченных органов, порядок деятельности саморегулируемых организаций (СРО), их права и обязанности, определен порядок обеспечения имуществснной ответственности при осуществлении оценочной деятельности, предусмотрено обязательное страхование ответственности оценщика при осуществлении оценочной деятельности.

Глава III.1 посвящена государственной кадастровой оценке. Отметим, что с 1 января 2017 года вступил в силу Федеральный закон от 03.07.2016 № 237-Ф3 «О государственной кадастровой оценке» [5]. Переходный период устанавливается с 1 января 2017 года до 1 января 2020 года. В течение переходного периода государствснная кадастровая оцснка может проводиться в соответствии с Федеральным законом от 03.07.2016 № 237-Ф3 или в соответствии с № 135-Ф3 с учетом особенностей, предусмотренных федеральными законами.

В четвертой главе приводятся заключительные положения Закона. Данный Закон является динамично развивающимся, практически каждый год в него вносятся поправки и дополнения.

Одним из важнейших механизмов регулирования оценочной деятельности также является система стандартов. Возможность проведения объективной оценки обеспечивается через важнейший принцип деятельности оценщиков - их независимость, что означает осуществление деятельности не согласно чьим-то пожеланиям и интерссам, а в соответствии с нормами и стандартами [6].

В связи с переходом к саморегулированию в сфере оценочной деятельности установлено деление стандартов оценочной деятельности на федеральные стандарты оценки, разрабатываемые НСОД (Национальным совстом по оценоч- 
ной деятельности) и утверждаемые Минэкономразвития России, и стандарты и правила оце- ночной деятельности, разрабатываемые и утверждаемые СРО (рис. 2) [7].

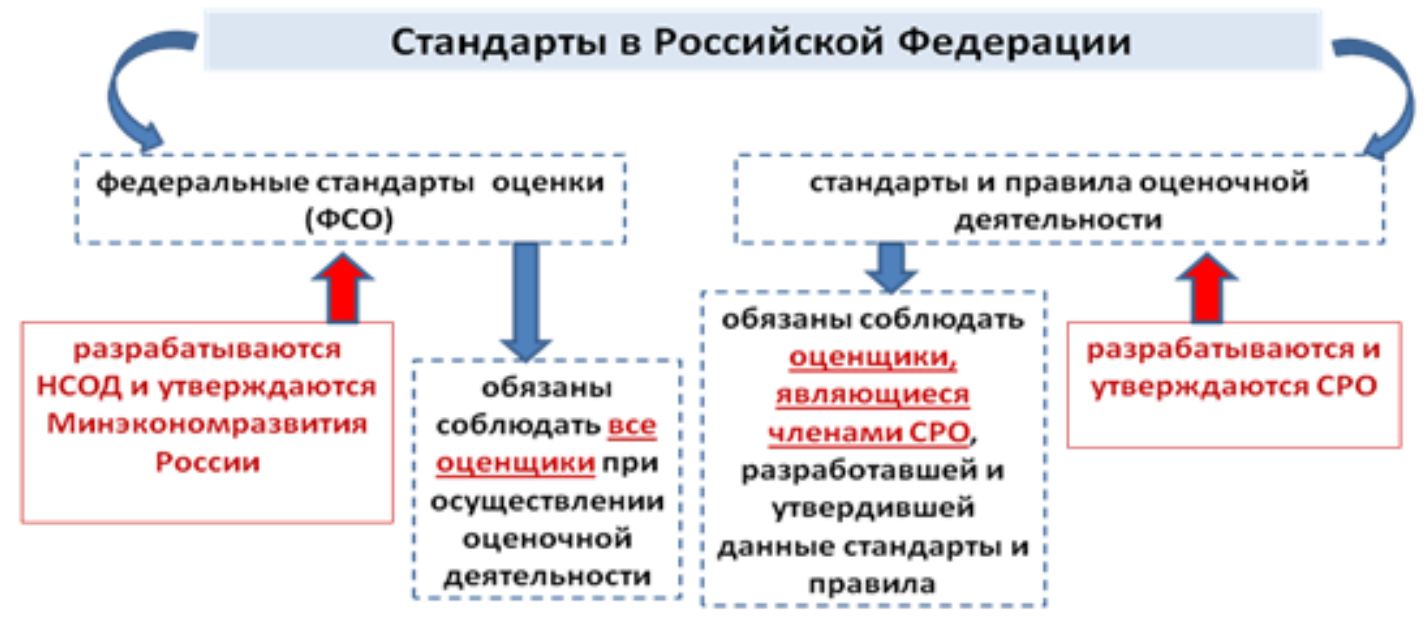

Рис. 2. Стандарты оценочной деятельности

Федеральные стандарты оценки (ФСО) разрабатываются на основе международных стандартов оценки, что обусловлено процессами интеграции России в международное экономическое сообщество. Требования федеральных стандартов оценки обязаны соблюдать все оценшики при осуществлении оценочной деятельности, а требования стандартов и правил оценочной деятельности - оценщики, являющиеся членами СРО, разработавшей и утвердившей данные стандарты и правила, т.е. требования стандартов и правил оценочной деятельности, разработанных и утвержденных СРО, обязаны соблюдать только те оценщики, которые являются членами данной СРО
Таким образом, логическим развитием положений, заложенных в Законе об оценке №135Ф3. явились стандарты оценки. В 2001 году постановлением Правительства России были утверждены первые из них, заложившие детализацию регулирования оценочной деятельности [8]. С 2007 года на смену указанным стандартам пришла совокупность полноценных Федеральных стандартов оценки (ФСО), систематически охватывающих различные аспекты оценочной деятельности. По состоянию на 2017 год утверждено 13 ФСО.

Законом об оценке проведена четкая грань между тремя уровнями системы регулирования оценочной деятельности и строго разграничены полномочия в этой сфере (рис. 3).

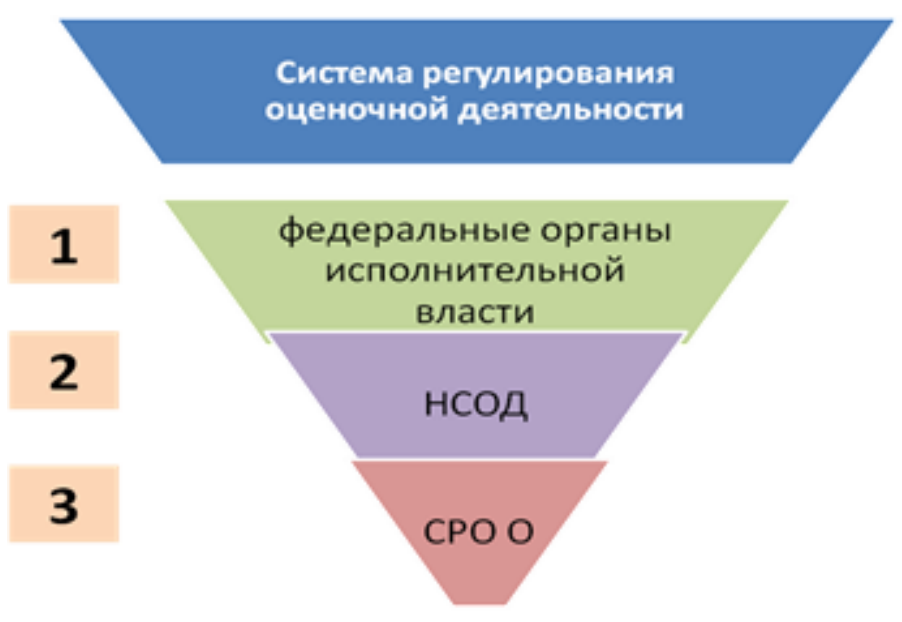

Рис. 3. Регулирование оценочной деятельности

Высший уровень в иерархии принадлежит федеральным органам исполнительной власти, уполномоченным Правительством РФ, осуществляющим государственное регулирование оценочной деятельности и деятельности саморегулируемых организаций оценщиков (СРО О) в части надзора и нормативно-правового регулирования. В соответствии со ст. 19 Закона функ- 
циями уполномоченных федеральных органов являются:

-выработка государственной политики в области оценочной деятельности:

- нормативно-правовое регулирование в области оценочной деятельности, утверждение федеральных стандартов оценки;

- ведение единого государственного реестра саморегулируемых организаций оценшиков;

- осушествление надзора за выполнением саморегулирусмыми организациями оценщиков требований законодательства;

- обращение в суд с заявлением об исключении саморегулируемой организации оценщиков из единого государственного реестра саморегулируемых организаций оценщиков.

Второй уровень - Национальный совет по оценочной деятельности (НСОД), осуществляющий регулирование оценочной деятельности в части разработки федеральных стандартов оценки [9]. Национальный совет является негосударственным институтом и создается саморегулируемыми организациями оценщиков в целях обеспечения обшественных интересов, формирования единых подходов к осуществлению оценочной деятельности, выработки единой позиции оценщиков по вопросам регулирования их деятельности, координации деятельности саморегулируемых организаций оценшиков, а также в целях взаимодействия саморегулируемых организаций оценщиков с федеральными органами государственной власти, органами государственной власти субъектов Российской Федерации, органами местного самоуправ.тения и потребителями услуг в области оценочной деятельности.

Определены функции НСОД, к которым отнесены:

- разработка федеральных стандартов оценки:

- рассмотрение проектов нормативных правовых актов, регулирующих оценочную деятельность, и рекомендация их к утверждению уполномоченным федеральным органом;

- рассмотрение обращений, ходатайств, жалоб саморегулируемых организаций оценщиков и потребителей соответствующих услуг, создание общероссийского третейского суда в сфере оценочной деятельности.

На третьем уровне системы регулирования оценочной деятельности находятся саморегулируемые организации оценщиков (СРО). К функциям таких организаций отнесены:

- разработка и утверждение стандартов и правил оценочной деятельности, правил и условий приема в члены организации;

- ведение реестра;
- определение прав и обязанностей таких организаций, в том числе: формирование компенсационного фонда для обеспечения ответственности своих членов, контроль за соблюдением членами организации требований законов, федеральных стандартов оценки, стандартов и правил оценочной деятельности. В некоторых случаях СРО вправе применять меры дисциплинарного воздействия к своим членам, исключать их из состава СРО, а также отказывать в принятии новых членов.

СРО выполняют как регулируюшие, так и контрольные функции.

К числу регулирующих функций СРО следует отнести:

- разработку и утверждение стандартов и правил оценочной деятельности, правил деловой и профессиональной этики;

- разработку и утверждение правил и условий приема в члены СРО, дополнительных требований к порядку обеспечения имущественной ответственности своих членов при осуществ.лении оценочной деятельности, установление размера членских взносов и порядка их внесения;

- представ.ление интересов своих членов в их отношениях с федеральными органами государственной власти, органами государственной власти субъектов Российской Федсрации, органами местного самоуправления, а также с международными профессиональными организациями оценщиков:

- организацию информационного и методического обеспечения своих членов.

Регулирующей является и функция оспаривания в суде актов органов государственной власти и органов местного самоуправления и действий (бездействие) этих органов, нарушающих права и законныс интерссы всех или части членов СРО.

Контрольными функциями СРО являются:

- контроль над осуществлением членами СРО оценочной деятельности в части соблюдения ими требований комментируемого Закона, других федеральных законов и иных нормативных правовых актов Российской Федерации, федеральных стандартов оценки, стандартов и правил оценочной деятельности, а также правил деловой и профессиональной этики;

- ведение реестра членов СРО и предоставление информации, содержашейся в этом реестре, заинтересованным лицам в порядке, установленном уполномоченным федеральным органом, осуществляющим функции по нормативно-правовому регулированию оценочной деятельности;

- прием в члены и исключение из членов СРО по основаниям, предусмотренным коммен- 
тируемым Законом и внутренними документами CPO.

К этой же группе функций относится и раскрытие информации СРО.

До конца 2007 года регулирование оценочной деятельности в России осуществлялось государством через механизм лицензирования.

Структурой, непосредственно выдававшей лицензии, а таюке осуществлявшей проверку

соблюдения лицензионных требований, являлось Федеральное агентство по управлению федеральным имуществом (Росимущество).

С 2008 года оценочная деятельность переведена на механизм саморегулирования - ряд функций по регулированию отрасли передан профессиональным объединениям оценшиков, имеющим статус саморегулируемых организаций (рис. 4).

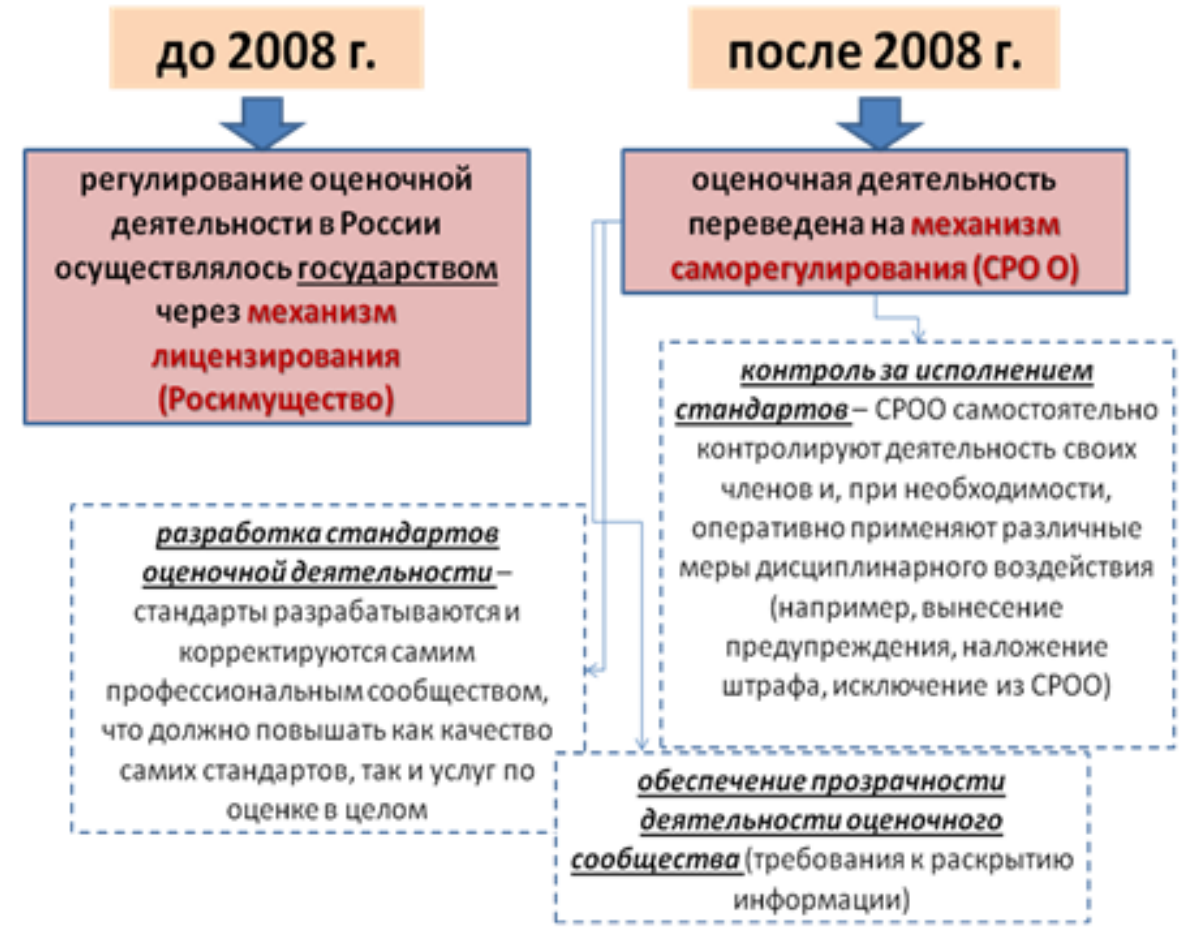

Рис. 4. Основные изменсния в регулировании оценочной деятельности в России

Таким образом, в общем виде сущность саморегулирования базируется на следующих основных положениях:

- разработка стандартов оценочной деятельности - стандарты разрабатываются и корректируются самим профессиональным сообществом, что должно повышать как качество самих стандартов, так и услуг по оценке в целом;

- контроль за исполнением стандартов СРОО самостоятельно контролируют деятельность своих членов и, при необходимости, оперативно применяют различныс мсры дисциплинарного воздействия (например, вынесение предупреждения, наложение штрафа, исключение из СРОО);

- обеспечение прозрачности деятельности оценочного сообщества (требования к раскрытию информации).

\section{БИБЛИОГРАФИЧЕСКИЙ СПИСОК}

1. Федеральный закон от 29.07.1998 № 135Ф3 (ред. от 03.07.2016, с изм. от 05.07.2016) «Об оценочной деятельности в Российской Федерации» (с изм. и доп., вступ. в силу с 01.01.2017)
[Электронный $\quad$ pecypc]. URL: http://www.consultant.ru

2. Сафарян К.В. Оценочная деятельность: понятие, нормативная база, механизмы регулирования [Электронный ресурc]. URL: http://lexandbusiness.ru/view-article.php?id=2279

3. Сафарян К.В. Инновационный бизнес: практические аспекты оценки активов [Электронный ресурc]. URL: https://profilib.com/chtenie/20893/karinasafaryan-innovatsionnyy-biznes-prakticheskieaspekty-otsenki-aktivov-2.php 4. Международным комитетом по стандартам оценки [Электронный pecypc]. URL: http://mirznanii.com/a/262933/mezhdunarodnymkomitetom-po-standartam-otsenki

5. Федеральный закон от 03.07.2016 № 237Ф3 «О государственной кадастровой оценке» [Электронный pecypc]. URL: http://www.consultant.ru 
6. Механизмы регулирования оценочной деятельности [Электронный ресурс]. URL: http://studbooks.net/958516/pravo/mehanizmy_regu lirovaniya_otsenochnoy_deyatelnosti

7. Саморегулирование в оценочной деятельности [Электронный pecypc]. URL: http://bfmac.com/otvety-na-voprosychitatelej/samoregulirovanie-v-otsenochnojdeyatelnosti.html

8. Стандарты оценки, обязательные к при- менению субъъектами оценочной деятельности, утвержденные постановлением Правительства Российской Федерации от 06.07.2001 г. №519 [Электронный ресурc]. URL: http://www.consultant.ru

9. Официальный сайт Национального совета по оценочной деятельности [Электронный pecypc]. URL: http://xn--d1ardl.xn-p1ai/?yclid=2850941304200498099

\section{Parfenyukova E.A., Shirina N.V.}

\section{LEGAL BASES AND REGULATION OF EVALUATION ACTIVITIES}

The fundamental provisions of regulating evaluation activities in the Russian Federation nowadays are presented, namely, the current system of evaluation activities regulation, consisting of the Federal Law №135$F Z$ and the system of standard documents, is considered; a clear demarcation between the three levels of evaluation activities regulation system and between the decision authorities in this sphere is provided.

Key words: evaluation activities, self-regulated organizations, Federal standards of evaluation, evaluation activities regulation.

Ширина Наталья В.ладимировна, кандидат технических наук, доцент

Белгородский государственный технологический университет им. В.Г. Шухова

Россия, 308012, Белгород, ул. Костюкова, д. 46

E-mail: schnv02@mail.ru

Парфенюкова Елизавета Артуровна, магистрант.

Белгородский государственшый технологический университет им. В.Г. Шухова

Россия, 308012, Белгород, ул. Костюкова, д. 46

E-mail: schnv02@mail.ru 